\title{
Correction to: "Women as Troublemakers": The Hard Sociopolitical Context of Soft Bipolar Disorder in Iran
}

\author{
Fahimeh Mianji ${ }^{1,2}$ Laurence J. Kirmayer ${ }^{1,2}$
}

Published online: 8 September 2021

(C) Springer Science+Business Media, LLC, part of Springer Nature 2021

\section{Correction to: Cult Med Psychiatry (2021) https://doi.org/10.1007/s11013-021-09743-4}

The original version of this article unfortunately contained an error, and it has been corrected with this erratum.

In the result section, the case 4 is labelled as case 5 and the affiliation "Culture and Mental Health Research Unit, Institute of Community and Family Psychiatry, 4333 Chemin de la Côte Ste-Catherine, Montreal, QC H3T 1E4, Canada for Dr. Laurence J. Kirmayer was missing.

The original article has been corrected.

Publisher's Note Springer Nature remains neutral with regard to jurisdictional claims in published maps and institutional affiliations.

The original article can be found online at https://doi.org/10.1007/s11013-021-09743-4.

Fahimeh Mianji

fahimehmianji@gmail.com

1 Division of Social and Transcultural Psychiatry, Department of Psychiatry, McGill University, Montreal, Canada

2 Culture and Mental Health Research Unit, Institute of Community and Family Psychiatry, 4333 Chemin de la Côte Ste-Catherine, Montreal, QC H3T 1E4, Canada 